\title{
28 Research Soure \\ Evaluation of Serum Biochemical Parameters and Metabolism in Smokers: A Case Control Study
}

Yılmaz Sezgin ( $\nabla$ drysezgin@gmail.com)

Research article

Keywords: Smoking tobacco, Biochemical parameters, metabolism

Posted Date: February 8th, 2022

DOl: https://doi.org/10.21203/rs.3.rs-982021/v1

License: (9) (i) This work is licensed under a Creative Commons Attribution 4.0 International License. Read Full License 


\section{Abstract \\ Background}

Smoking tobacco is a substantial risk factor for chronic obstructive pulmonary disease and cardiovascular diseases. For this reason, studies on smoking are mostly focused on the pulmonary and cardiovascular systems. Recently, an increase has been observed in the number of studies investigating the relationship between obesity and diabetes and smoking. We investigated the effects of smoking on other serum biochemical parameters and metabolism.

\section{Methods}

This is a case-control study. The case and control groups were formed by clinical randomization by using the data obtained from the hospital information system and patient records, including age, gender, height, and weight. Smokers were identified as the case group, while non-smokers were identified as the control group. In the comparisons of rates Chi-square tests were used and in the comparisons of averages, independent sample t and MANCOVA tests were used.

\section{Results}

When covariance factors such as age, gender, body mass index, and alcohol use were taken into consideration, It found that AST, ALT, and GGT were higher in smokers, whereas vitamin D, vitamin B12, and TSH were higher in non-smokers.

\section{Conclusions}

We found that smoking has a negative effect on liver and bile functions, and vitamin D values are affected secondary to this negative effect.

\section{Background}

More than 5,000 chemical compounds have been identified in tobacco and tobacco smoke [1]. The most well-known of these substances is nicotine and identified with cigarettes. Nicotine is responsible for the addictive effect of smoking [2]. Smoking is one of the most important risk factors for chronic obstructive pulmonary disease $[3,4]$. Smoking is accepted to increase the risk of cardiovascular diseases $[5,6]$.

Studies investigating the effects of smoking are mostly focused on the pulmonary and cardiovascular system. The number of studies on the effects of smoking on other systems such as the gastrointestinal system and urinary system than the pulmonary and cardiovascular system is not sufficient to establish a consensus on the effects of cigaret on these systems. Recently, the number of studies investigating the 
relationship between smoking and obesity and diabetes has been observed to be increased $[7,8]$. We investigated the effects of smoking on several serum biochemical parameters and metabolism.

\section{Methods}

\section{Study Design}

This was designed to be a case-control study.

\section{Population selection}

The case and control groups were formed by clinical randomization by using the data obtained from the hospital information system and patient records, including age, gender, height and weight. The case group included 30 individuals with smoking habit and a control group consisted of non-smokers, matching with the case group in terms of number, gender, age and body mass index (BMI). Patients with any known disease and those using medications were not included in the study. Laboratory data of individuals who met the inclusion criteria among patients who admitted to the family medicine outpatient clinic during the last three-months were evaluated for analysis.

\section{Laboratory testing}

The blood samples of the participants were collected at the time of admission. A total of 19 parameters, including creatinine, urea, AST, ALT, GGT, sodium, potassium, albumin, cholesterol, triglyceride, HDL-C, LDL-C, HbA1C, glucose, insulin, vitamin D, vitamin B12, TSH, and free T4 were measured simultaneously for the analysis.

\section{Statistical analysis}

All statistical analyzes were performed by using IBM SPSS software (V25). A value of $P<.05$ was considered statistically significant. Categorical data were expressed by numbers and percentages. In the comparison of categorical variables chi-square test was used. Numerical data were expressed by mean values. In the comparison of the means independent sample $t$ and MANCOVA tests were used. The compliance of the variances with normal distribution was tested by using box's and levene's tests.

\section{Results}

There was no difference between the case and control groups in terms of gender and BMI. However, the rate of alcohol use was lower in the case group compared to the control group. The mean age was higher in the case group compared to the control group (Table 1). 
Table 1

Comparison of the age, $\mathrm{BMl}$, gender and using alcohol in between case and control groups

\begin{tabular}{|llll|}
\hline Characteristics of participants. & Case $(\mathbf{n}=\mathbf{3 0})$ & Control $(\mathbf{n}=\mathbf{3 0})$ \\
\hline Age: Mean (SD)* & & $25.80(3.84)$ & $22.30(5.54)$ \\
\hline BMI: Mean (SD) & Female & $15(25)$ & $22.66(2.69)$ \\
\hline Gender: $\mathrm{n}(\%)$ & Male & $15(25)$ & $15(25)$ \\
\cline { 2 - 4 } & Yes & $7(11.7)$ & $15(25)$ \\
\hline Alcohol: $n(\%)^{*}$ & No & $23(38.3)$ & $14(23.3)$ \\
\hline SD: Standard Deviation; *The statistical significant different was accepted as $P<.05$ level (2-tailed) \\
\hline
\end{tabular}

According to independent sample t test analysis between smokers and non-smokers; were found significant differences in terms of serum AST, ALT, GGT, LDL-C, vitamin D, vitamin B12 and TSH levels. We found that AST, ALT GGT, and LDL-C levels were higher in the case group, whereas vitamin D, vitamin B12 and TSH levels were higher in the control group (Table 2). 
Table 2

Comparison of the serum biochemical parameters in between case and control groups

\begin{tabular}{|c|c|c|c|c|}
\hline & Case $(n=30)$ & Control $(n=30)$ & \multirow[t]{2}{*}{$t$} & \multirow[t]{2}{*}{$P$ value } \\
\hline & \multicolumn{2}{|l|}{ Mean (SD) } & & \\
\hline Creatinine (mg/dL) & $0.71(0.27)$ & $0.69(0.26)$ & 0.15 & .881 \\
\hline Urea (mg/dL) & $27.63(8.35)$ & $24.20(5.30)$ & 1.90 & .062 \\
\hline AST (U/L) & $25.90(10.84)$ & $17.70(5.42)$ & 3.70 & $.001 *$ \\
\hline ALT (U/L) & $22.50(10.01)$ & $15.30(6.04)$ & 3.37 & $.001^{\star}$ \\
\hline GGT (U/L) & $19.80(7.07)$ & $15.06(5.31)$ & 2.92 & $.005^{\star}$ \\
\hline Sodium (mmol/L) & 140.60 (3.94) & $140.23(2.69)$ & 0.42 & .676 \\
\hline Potassium (mmol/L) & $4.18(0.29)$ & $4.22(0.38)$ & -0.41 & .684 \\
\hline Albumin $(g / L)$ & $4.38(0.35)$ & $4.34(0.22)$ & 0.40 & .688 \\
\hline Cholesterol (mg/dL) & $157.50(24.03)$ & $155.46(23.09)$ & 0.33 & .740 \\
\hline Triglycerides (mg/dL) & $84.10(26.37)$ & $73.16(34.15)$ & 1.38 & .171 \\
\hline HDL-C (mg/dL) & $55.66(12.48)$ & $53.26(10.92)$ & 0.79 & .431 \\
\hline LDL-C (mg/dL) & $90.43(18.33)$ & $78.96(21.70)$ & 2.21 & $.031^{\star}$ \\
\hline HbA1C (\%) & $5.17(0.41)$ & $5.29(0.21)$ & -1.41 & .163 \\
\hline Glucose (mg/dL) & $87.20(6.89)$ & $84.96(8.60)$ & 1.10 & .272 \\
\hline Insulin ( $\mu \mathrm{U} / \mathrm{mL})$ & $9.09(5.98)$ & 7.95 (7.39) & 0.65 & .512 \\
\hline Vitamin $\mathrm{D}(\mathrm{ng} / \mathrm{mL})$ & $14.50(3.34)$ & $18.76(9.01)$ & -2.42 & $.019 *$ \\
\hline Vitamin B12 (ng/L) & $110.30(52.03)$ & $167.66(78.85)$ & -3.32 & $.002^{\star}$ \\
\hline TSH (mIU/L) & $1.27(0.47)$ & $1.93(0.86)$ & -3.62 & $.001^{\star}$ \\
\hline Free T4 (ng/dL) & $0.81(0.15)$ & $0.82(0.14)$ & -0.16 & .869 \\
\hline HOMA-IR & $1.97(1.34)$ & $1.75(2.04)$ & 0.47 & .635 \\
\hline
\end{tabular}

According to one-way MANCOVA analysis performed by taking into consideration covariance factors including age, gender, BMI and alcohol use between smokers and non-smokers were found significant differences in terms of serum biochemical parameters. The assumption of variance equality could not be met, since the value of $P$ obtained from the box's test result was less than $.05(P=.001)$. In this case, pillai's trace results were taken into account for MANCOVA test statistics (pillai's trace $=0.57, F[20,35]=$ 
2.36, $\mathrm{P}=.013)$. When the covariance factors were considered, we found that the difference between the two groups continued for AST, ALT, GGT, vitamin D, vitamin B12, and TSH, whereas the difference did not continued for LDL-C (Table 3).

Table 3

Comparison of serum biochemical parameters between case and control groups, taking into account covariate factors

\begin{tabular}{|c|c|c|c|c|c|}
\hline & Case $(n=30)$ & Control $(n=30)$ & Levene's & $\mathbf{F}$ & $P$ value \\
\hline & $\operatorname{Mean}^{\mathrm{a}}(\mathrm{SE})$ & & & & \\
\hline Creatinine (mg/dL) & $0.69(0.04)$ & $0.71(0.04)$ & 0.901 & 0.13 & .713 \\
\hline Urea (mg/dL) & $27.46(1.23)$ & $24.37(1.23)$ & 0.001 & 2,85 & .097 \\
\hline AST (U/L) & $25.97(1.65)$ & $17.62(1.65)$ & 0.040 & 11.67 & $.001^{*}$ \\
\hline ALT (U/L) & $22.73(1.59)$ & 15.06 (1.59) & 0.002 & 10.63 & $.002 *$ \\
\hline GGT (U/L) & $19.51(1.08)$ & $15.34(1.08)$ & 0.532 & 6.72 & $.012^{\star}$ \\
\hline Sodium (mmol/L) & $140.68(0.60)$ & $140.15(0.60)$ & 0.085 & 0.34 & .558 \\
\hline Potassium (mmol/L) & $4.20(0.06)$ & $4.19(0.06)$ & 0.053 & 0.01 & .916 \\
\hline Albumin $(g / L)$ & $4.38(0.05)$ & $4.34(0.05)$ & 0.392 & 0.22 & .641 \\
\hline Cholesterol (mg/dL) & $156.99(4.54)$ & $155.97(4.54)$ & 0.842 & 0.02 & .880 \\
\hline Triglycerides (mg/dL) & $83.98(5.85)$ & $73.28(5.85)$ & 0.134 & 1.52 & .222 \\
\hline HDL-C (mg/dL) & $55.48(0.05)$ & $53.45(0.05)$ & 0.803 & 0.36 & .547 \\
\hline LDL-C (mg/dL) & $89.44(3.90)$ & 79.95 (3.90) & 0.463 & 2.70 & .106 \\
\hline HbA1C (\%) & $5.17(0.05)$ & $5.30(0.05)$ & 0.024 & 2.43 & .124 \\
\hline Glucose (mg/dL) & $87.37(1.53)$ & $84.78(1.53)$ & 0.147 & 1.30 & .259 \\
\hline Insulin $(\mu \mathrm{U} / \mathrm{mL})$ & $9.38(1.29)$ & $7.66(1.29)$ & 0.843 & 0.80 & .373 \\
\hline Vitamin D (ng/mL) & $14.74(1.23)$ & $18.52(1.23)$ & 0.070 & 4.29 & $.043^{\star}$ \\
\hline Vitamin B12 (ng/L) & $105.80(12.37)$ & 172.16 (12.37) & 0.045 & 13.18 & $.001^{*}$ \\
\hline TSH (mlU/L) & $1.30(1.12)$ & $1.89(1.12)$ & 0.006 & 10.91 & $.002^{\star}$ \\
\hline Free T4 (ng/dL) & $0.80(0.02)$ & $0.82(0.02)$ & 0.777 & 0.23 & .629 \\
\hline HOMA-IR & $2.03(0.33)$ & $1.69(0.33)$ & 0.853 & 0.46 & .496 \\
\hline
\end{tabular}


There was no significant difference between the case group and the control group in terms of glycemic parameters. However, HOMA-IR values were higher in the case group while HbA1C values were higher in the control group (Table 3).

\section{Discussion}

The fact that the alcohol use rate was lower and the average age was higher in the case group in comparison to the control group, indicates that randomization was not performed very well. However, this limitation has been minimized by one-way MANCOVA analyzes performed by considering covariance factors such as age, gender, BMI and alcohol use.

In our study, the higher values of serum AST, ALT, and GGT observed in the case group indicates that smoking affects liver and bile functions, negatively. In the literature there are studies that support our results. In a study conducted on males, GGT was higher in smokers in comparison to non-smokers [9]. It has also been suggested that smoking causes cellular damage by causing oxidative stress and ultrastructural changes on hepatocytes [10].

In our study, the lower serum vitamin $D$ values in the case group compared to the control group may be caused by a defect in the vitamin D synthesis in the liver and / or an absorption disorder. Cholecalciferol synthesized in the epidermis or taken with diet turns into 25-hydroxycholecalcidiol in the liver and then to 1,25-hydroxycholecalcitriol as the active form in the kidney [11]. The 25-hydroxycholecalcididol transformation that takes place in the liver may be impaired due to the negative effects of smoking on hepatocytes. In addition, absorption of Vitamin D, a fat-soluble molecule, may be impaired due to the negative effects of smoking on the biliary system. In the literature, there are a few studies supporting our results, related to vitamin $D$ in our study. However, the reasons for vitamin D deficiency in smokers have not been fully clarified in these studies [12].

We found that, serum vitamin B12 values were lower in the case group compared to the control group. These our results are in line with the knowledge in the literature. There are studies suggesting that smoking, which is a source of free radicals, causes serum vitamin B12 levels to decrease [13-15]. The use of tobacco causes the serum cyanide level to increase due to the cyanide it contains. It has been shown that high cyanide levels increase the excretion of thiocyanate from the kidneys, which is associated with a decrease in serum vitamin B12 level [16].

We found that serum TSH levels were lower in the case group compared to the control group. In the literature, it has been reported that the effects of smoking on thyroid tissue are complex, while smoking generally increases susceptibility to hypertroidism $[17,18]$. This relationship between smoking and thyroid functions may be due to vitamin B12 deficiency seen in smokers. Although there is a widespread opinion in the literature that vitamin B12 deficiency and increased levels of homocysteine increase susceptibility to hypothyroidism and autoimmune thyroid diseases, studies on animals suggest contradictory evidence [19-21]. In addition, S adenosyl methionine, a product of the homocysteine 
methionine cycle with additive vitamin B12 cofactor stimulates TRH and therefore TSH release and TSH receptor interaction [22].

In our study, we found no difference in kidney function, between smokers and non-smokers. In the literature, it has been reported that kidney functions are affected by smoking due to the increase in nicotine-induced adrenergic activity [23].

In our study, no significant difference was found between smokers and non-smokers in terms of serum glycemic index and lipid profile. However, HOMA-IR values were higher in the case group while HbA1C values were higher in the control group. HOMA-IR values show the momentary state, while HbA1C shows the last three-month period. These findings indicate that there was a predisposition to hypoglycaemia in the smoker group in the past. In a study conducted on obese people, HOMA-IR was found to be higher in smokers compared to non-smokers, but there was no significant difference in serum glucose, insulin, total cholesterol, triglyceride, HDL-C, and LDL-C levels [24]. Nicotine causes hyperglycemia by increasing gluconeogenesis by stimulating catecholamine-mediated glucagon release from the adrenergic medulla [8]. It is plausible that the relationship between smoking and insulin resistance, which is frequently emphasized in the literature, may be a result rather than a cause. Given the assumption that hyperinsullinemia-induced hypoglycaemia episodes seen at the onset of type 2 diabetes can be prevented by increasing gluconeogenesis, nicotine may be preferred due to an avoidance behavior.

\section{Conclusions}

As a result, we suggest that smoking has a negative effect on liver and bile functions, and vitamin D values are affected secondary to this negative effect. In addition, the relationship between smoking and thyroid functions may be due to vitamin B12 deficiency seen in smokers.

\section{Abbreviations}

BMI

Bbody mass index

AST

Aspartate aminotransferase

ALT

Alanine aminotransferase

GGT

Gamma-glutamyl transferase

HDL-C

High-density lipoprotein cholesterol

LDL-C

Low-density lipoprotein cholesterol

TSH 
Thyroid stimulating hormone

$\mathrm{HbA1C}$

Glycosylated hemoglobin

HOMA-IR

Homeostatic model assessment for insulin resistance

TRH

Thyrotropin releasing hormone

\section{Declarations}

\section{Acknowledgments}

None

\section{Authors' contributions}

The concept and design of the study: Y.S. and S.B.; Data acquisition: Y.S., S.B. and A.P.; Statistical analysis: Y. S.; Analyzed the data and drafted the manuscript: Y.S., S.B. and A.P. All authors read and approved the final version of the manuscript

\section{Funding}

There is no funding

\section{Availability of data and materials}

The dataset is available from the corresponding author on reasonable request.

\section{Ethical approval}

The study was approved by the Istanbul Training Research Hospital Clinical Research Ethics Committee (Decision no: 2153). Informed consent was not obtained because of retrospective study.

\section{Consent for publication}

Not applicable.

\section{Conflicts of Interest}

The authors declare that no conflicts of interest.

\section{References}

1. Talhout R, Schulz T, Florek E, Benthem JV, Wester P, Opperhuizen A. Hazardous compounds in tobacco smoke. Int J Environ Res Public Health. 2011;8:613-28. 
2. Benowitz NL, Henningfield JE. Reducing the nicotine content to make cigarettes less addictive. Tob Control. 2013;22:14-7.

3. Salvi S. Tobacco smoking and environmental risk factors for chronic obstructive pulmonary disease. Clin Chest Med. 2014;35(1):17-27.

4. Laniado-Laborín R. Smoking and chronic obstructive pulmonary disease (COPD). Parallel epidemics of the 21st century. Int J Environ Res Public Health. 2009;6:209-24.

5. Banks E, Joshy G, Korda RJ, Stavreski B, Soga K, Egger S. etal.Tobacco smoking and risk of 36 cardiovascular disease subtypes: fatal and non-fatal outcomes in a large prospective Australian study. BMC Med. 2019;17(1):128.

6. Messner B, Bernhard D. Smoking and cardiovascular disease: mechanisms of endothelial dysfunction and early atherogenesis. Arterioscler Thromb Vasc Biol. 2014;34(3):509-15.

7. Lee H, Joe KH, Kim W, Park J, Lee DH, Sung KW. etal.Increased leptin and decreased ghrelin level after smoking cessation. Neurosci Lett. 2006;409(1):47-51.

8. Fagard RH, Nilsson PM. Smoking and diabetes-The double health hazard! Primary care diabetes. 2009;3:205-09.

9. Lee D, Kang HW, Kim II. Association between cigarette smoking and serum gamma glutamyl transferase level. Int J Respir Pulm Med. 2019;6:125. Y.

10. Battah KA, Badran DH, Shraideh ZA. Effect of cigarette smoking on the structure of hepatocytes: TEM study. Int J Morphol. 2016;34(4):1239-44.

11. Heath KM, Elovic EP. Vitamin D deficiency: Implications in the rehabilitation setting. Am J Phys Med Rehabil. 2006;85:916-23.

12. Brot $\mathrm{C}$, Jorgensen $\mathrm{NR}$, Sorensen $\mathrm{OH}$. The influence of smoking on vitamin $\mathrm{D}$ status and calcium metabolism. Eur J Clin Nutr. 1999;53(12):920-6.

13. Pivathilake HJ, Macaluso M, Hine RJ, Richards EW, Krumdieck CL. Local and systemic effects of cigarette smoking on folate and vitamin B12. Am J Clin Nutr. 1994;60:559-66.

14. Mcgarry JM, Andrews J. Smoking in pregnancy and vitamin B12 metabolism. BMJ. 1972;2:74-7.

15. Sezgin Y. Approach to Vitamin B12 Deficiency. Konuralp Medical J. 2019;11(3):482-8.

16. Linnell JC, Smith AD, Smith CL, Wilson J, Matthews DM. Effects of smoking on metabolism and excretion of vitamin B12. BMJ. 1968;2:215-6.

17. Gülcü F, Polat SA, Gürsü MF. Aşırı sigara kullanımının tiroid fonksiyon testleri ile eser element düzeylerine etkileri. Turkiye Klinikleri J Med Sci. 2003;23(5):386-91.

18. Kim BH, Kim WB, Kim TY, Kim HK, Jeon SH, Lee CW. etal.Association between Cigarette Smoking and Thyroid Function in Adults without Previous History of Thyroid Disease. Endocrinol Metab. 2008;23(2):123-8.

19. Collins AB, Pawlak R. Prevalence of vitamin B12 deficiency among patients with thyroid dysfunction. Asia Pac J Clin Nutr. 2016;25(2):221-6. 
20. Atabek ME, Pirgon O, Erkul I. Plasma homocysteine concentrations in adolescents with subclinical hypothyroidism. J Pediatr Endocrinol Metab. 2003;16(9):1245-8.

21. Jacobs RL, Stead LM, Brosnan ME. etal.Plasma homocysteine is decreased in the hypothyroid rat. Can J Physiol Pharmacol. 2000;78(7):565-70.

22. Prasad C, Mori M, Greeley GH Jr, Edwards RM, Wilber JF, Pegues J. Biochemical transmethylation of lipids and neuropeptidergic stimulation of pituitary hormone secretion. Brain Res. 1985;334(1):41-6.

23. Cooper RG. Effect of tobacco smoking on renal function. Indian J Med Res. 2006;124(3):261-8.

24. Yağbasan Y, Ersoy C, Çubukçu E, Ölmez ÖF, İmamoğlu Ş. Morbid obez kadınlarda sigara içiminin obezite indeksleri, insülin direnci, kan basıncı, glisemi ve lipid parametreleri üzerine etkilerinin retrospektif olarak değerlendirilmesi. İnönü Üniversitesi Tıp. Fakültesi Dergisi. 2008;15(4):245-8. 